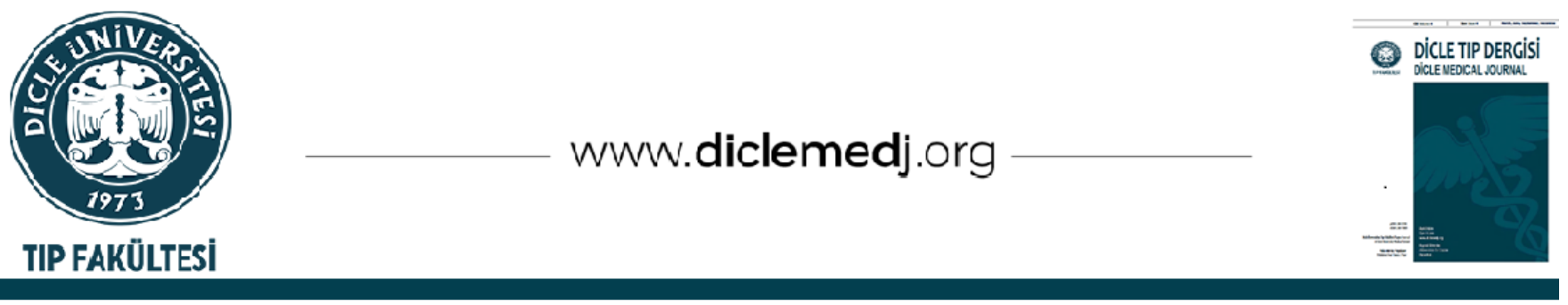

\title{
İnguinal herni onarımında USG eşliğinde TAP blok, USG eşliğinde yara yeri infiltrasyonu ve intravenöz deksketoprofenin preemptif uygulanmasının postoperatif analjezik etkinliklerinin karşılaştırılması
}

\author{
Fikret Salık ${ }^{D}{ }_{1}$, Mustafa Bıçak ${ }^{D}{ }_{1}$, Hakan Akelma ${ }^{1}{ }_{1}$, Sedat Kaya ${ }^{1}$ \\ 1 Sağlık Bilimleri Üniversitesi Gazi Yaşargil Eğitim ve Araştırma Hastanesi Anesteziyoloji ve Reanimasyon ABD. Diyarbakır, Türkiye \\ Geliş: 29.06.2020; Revizyon: 23.01.2021; Kabul Tarihi: 27.01.2021
}

öz

Amaç: İnguinal herni onarımlarında ideal postoperatif analjezi yöntemi halen tartışma konusudur. Bu çalışmada, kasık fitığı onarımlarında preemptif olarak uyguladı̆̆ımız farklı analjezik yöntemlerin postoperatif analjezik etkinliğini karşılaştırmayı amaçladık.

Yöntemler: Bu çalışma prospektif olarak dizayn edildi. Çalışmaya spinal anestezi eşliğinde elektif inguinal herni onarımı yapılan 1875 yaş arası hastalar alındı. 120 hasta cerrahi insizyondan önce uygulanan analjezik yönteme göre üç gruba ayrıldı. Grup 1: USG kılavuzluğunda Transversus abdominis plan bloğu ( $n=40)$, Grup 2: USG kılavuzluğunda lokal anestezik infiltrasyon ( $n=40)$ ve Grup 3 intravenöz deksketoprofen $(\mathrm{n}=40)$. Postoperatif 24 saat boyunca ortalama tramadol tüketim miktarı ve kurtarıcı analjezik ihtiyacı olan hasta sayısı kaydedildi. Hastaların 30. dakika. 1, 2, 4, 8, 12, 16, ve 24. saat VAS skorları analiz edildi.

Bulgular: Postoperatif ortalama tramadol tüketimi gruplar arasında istatistiksel olarak benzerdi [Grup 1: $22.5 \pm 57.6$ mg; Grup 2:

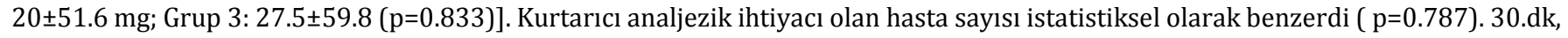
1, 2, 4, 8. ve 12. saatlerdeki VAS skorları Grup 1'de diğer gruplara göre istatistiksel olarak daha düşük saptandı (p değerleri sırasıyla 0.003, 007, 0013, 0049, 0015, 0021). Grup 1'de 30.dk ve 2. saatteki VAS skorları Grup 2'ye göre daha düşük saptandı (p değerleri sırasıyla 0.049, 0.037). Aynı zamanda 30.dk, 1, 2, 8. ve 12. saatlerdeki VAS skorları Grup 1'de Grup 3'e göre daha düşük tespit edildi (p değerleri sırasıyla 0.003, 0.006, 0.021, 0.017, 0.016). Tüm saatlerdeki VAS skorları Grup 2 ile Grup 3 arasında istatistiksel olarak benzer bulundu.

Sonuç: Bu çalışmada, inguinal herni onarımlarında postoperatif analjezi amacıyla preemptif olarak transversus abdominis plan bloğu, lokal anestezik ilaç infiltrasyonu veya intravenöz deksketoprofenin postoperatif tramadol tüketim miktarı ve kurtarıcı analjezik ihtiyacı olan hasta sayısı üzerine etkilerinin benzer olduğunu gösterdik. Ancak transversus abdominis plan bloğu, postoperatif ilk 24 saatte daha düşük VAS skorları ve daha fazla sayıda hastada mükemmel analjezi sağlamaktadır.

Anahtar kelimeler: İnguinal herni onarımı; preemptif analjezi; transvers abdominis plan bloğu; intravenöz deksketoprofen.

DOI: 10.5798/dicletip.887351

Correspondence / Yazışma Adresi: Fikret Salık, Sağlı Bilimleri Üniversitesi Gazi Yaşargil Eğitim ve Araştırma Hastanesi Anesteziyoloji ve Reanimasyon ABD. Diyarbakır, Türkiye e-mail: fikretsalik@gmail.com 


\section{Comparison of postoperative analgesic efficacy of preemptive USG-guided TAP block, USG- guided local infiltration and intravenous dexketoprofen in inguinal hernia repair}

Abstract

Objective: The ideal postoperative analgesic method in inguinal hernia repairs is still controversial. We aimed in this study to comparison the postoperative analgesic efficacy of different analgesic methods that we performed preemptively in inguinal hernia repairs.

Methods: This study was designed prospectively. Patients aged 18-75 years who underwent elective inguinal hernia repair under spinal anesthesia were included in the study. 120 patients were divided into three groups according to the analgesic method performed before surgical incision. Group 1: USG-guided Transversus abdominis plane block $(\mathrm{n}=40)$, Group 2: USG-guided local anesthetic infiltration $(n=40)$ and Group 3 intravenous dexketoprofen $(n=40)$. The mean of tramadol consumption and number of patients in requiring rescue analgesics were recorded for 24 hours postoperatively. VAS scores were analyzed at the 30 minute, 1, 2, 4, 8, 12, 16 and 24th hours.

Results: The postoperative mean tramadol consumption was statistically similar between the groups [Group 1: 22.5 $\pm 57.6 \mathrm{mg}$; Group 2: $20 \pm 51.6 \mathrm{mg}$; Group 3: $27.5 \pm 59.8 \mathrm{mg}(\mathrm{p}=0.833)]$ in groups. There was no significant difference between the number of patients requiring rescue analgesics ( $\mathrm{p}=0.787$ ). VAS scores at 30 . $\mathrm{min}, 1,2,4,8$ and 12 hours were statistically lower in Group 1 than in the other groups ( $\mathrm{p}$ values $0.003,007,0013,0049,0015,0021$ respectively). VAS scores at 30 . min and 2. h were lower in Group 1 than Group 2 (p values $0.049,0.037$ respectively). İ addition, VAS scores at 30 min, 1, 2, 8 and 12 hours were lower in Group 1 than in Group 3 (p values $0.003,0.006,0.021,0.017,0.016$ respectively). VAS scores at all hours were statistically similar between Group 2 and Group 3.

Conclusion: In this study, we demonsrated that preemptive transversus abdominis plane block, local anesthetic infiltration or intravenous dexketoprofen for postoperative analgesia in inguinal hernia repairs had similar effects on postoperative tramadol consumption and number of requiring rescue analgesic patients. However, the transversus abdominis plane block block provides lower VAS scores and excellent analgesia in more patients in the first 24 hours postoperatively.

Key words: Inguinal hernia repair, intravenous dexketoprofen, preemptive analgesia, transversus abdominis plan block.

\section{GíRiş}

İnguinal herni onarımı, günümüzde daha az invaziv tekniklerle (Lichtenstein tekniği) ve günübirlik yapılmasına rağmen karın duvarı insizyonuna bağlı orta veya şiddetli derecede ağrıya neden olabilir ${ }^{1,2}$. Operasyonun spinal anestezi eşliğinde uygulanması her ne kadar belirli bir süre postoperatif analjezi sağlasa da spinal anestezinin etkisi geçtikten sonra hastalar şiddetli ağrıyla karşı karşıya kalabilirler. Etkin postoperatif analjezi sağlanmadığı takdirde bu ağrı, günlük aktiviteleri sınırlayıp kronik ağrı gelişimine neden olarak yaşam kalitesini bozabiliri-3. Bu durum hastanede kalış süresini ve hastane maliyetlerini de arttırabilir. Bu yüzden efektif postoperatif analjezi yönetimi, hastanın günlük yaşamına erken dönmesini ve sağlık giderlerinin azalmasını sağlayabilecektir ${ }^{4}$.

Günümüzde inguinal herni onarımlarında postoperatif analjezi amacıyla farmakolojik ve rejyonel tekniklerin yanı sira multimodal teknikler de kullanılmaktadır ${ }^{1}$. Bu tekniklerden biri olan transversus abdominis plan (TAP) bloğu, son yıllarda sıklıkla kullanılmaktadır5. TAP bloğu, karın duvarı kaslarından internal oblik ve transversus abdominis kasları arasındaki fasyaların lokal anestezik ilaçlarla hidrodiseksiyonu prensibiyle gerçekleștirilmektedir ${ }^{6,7}$. Lokal anestezik ilaçlar fasyal düzlemde seyreden T6-L1 sinirlerini bloke ederek postoperatif dönemde 24 saate kadar analjezik etki sağlamaktadır5,8. TAP blok, ilk olarak petit üçgeni noktasından landmark tekniği ile uygulanmasına rağmen, USG kullanımının yaygınlaşmasıyla görüntüleme eşliğinde basit ve güvenilir bir şekilde uygulanmaktadır ${ }^{7}$. Rejyonel anestezik tekniklerden lokal anestezik ilaç infiltrasyonu (LAİ), diğer bir postoperatif analjezi yöntemidir. $\mathrm{Bu}$ işlem operasyon kesi hatlarına çoğunlukla cerrahi ekip tarafından uygulanmaktadır ${ }^{9,10}$. Bu 
iki uygulamanın dışında intravenöz analjezik ilaç(IVAI) uygulaması da çoğu klinikte farmakolojik postoperatif analjezi yöntemi olarak kullanılmaktadır ${ }^{1,11} . \quad \mathrm{Bu}$ amaçla nonsteroid antiinflamatuar ilaçlar (nsaii), parasetamol, siklooksijenaz inhibitörleri, opioidler, glukokortikoidler, klonidin, magnezyum, gabapentin ve pregabalin gibi çeşitli ilaçlar kullanılmaktadır ${ }^{1,11,12}$. Bu ilaçlardan biri olan deksketoprofen farklı cerrahi işlemlerde postoperatif analjezi sağlamak için kullanılmıştır ${ }^{13}$.

Cerrahi işlem başlamadan önce sistemik analjezik ilaçlar veya rejyonel teknikler ile analjezik kontrol sağlama prensibine dayanan preemptif analjezi gün geçtikçe önem kazanmaktadır ${ }^{14}$. İnguinal herni operasyonlarında her üç yöntemin de preemptif olarak kullanıldığı birçok çalışma mevcuttur ${ }^{1,12}$. Ancak önceki çalışmalarda farklı türlerde nsaii kullanılmasına rağmen intravenöz deksketoprofenin(IVD) preemptif olarak uygulandığı herhangi bir çalışmaya rastlayamadık. Aynı zamanda TAP blok, LAİ infiltrasyonu ve IVD'yi preemptif analjezi amacıyla karşılaştıran herhangi bir çalışma da bulamadik.

$\mathrm{Bu}$ çalışmamızda, spinal anestezi altında gerçekleştirilen inguinal herni onarımlarında USG eşliğinde TAP blok, cerrahi kesi hattına LAİ infiltrasyonu ve IVD uygulamalarının postoperatif analjezik etkinlik ve kurtarıcı opioid tüketimi üzerine etkilerini karşılaştırmayı amaçladık.

\section{YÖNTEMLER}

Prospektif ve gözlemsel olarak planlanan bu çalışma için Diyarbakır Gazi Yaşargil Eğitim ve Araştırma Hastanesi'nde etik kurul onayı alındı. Hastalardan yazılı bilgilendirilmiş onam alındıktan sonra, inguinal herni onarımı yapılan 18-75 yaş arası ve American Society of Anesthesiologist (ASA) I-III olan 131 hastada gerçekleștirildi. Çalışma Helsinki II deklarasyonuna uygun yapıldı.

18 yaş altı ve 75 yaş üstü, ASA IV, kullanılacak ajanlara karşı bilinen allerji öyküsü, son 48 saatte analjezik ilaç kullanım öyküsü, morbit obez (BMI>35), şuur bulanıklığı, koagülopati, işlem yerinde lokal enfeksiyonu olan ve bilateral inguinal herni operasyonu olan hastalar çalışma dışım bırakıldı. Ek olarak kalp, akciğer, hematolojik, metabolik ve endokrin problemi olan hastalar da çalışmaya alınmadı. Ayrıca çalışmaya dâhil olmak istemeyen, spinal anestezi işlemini reddeden ve spinal anestezi işlemi başarısız olan hastalar çalışma dışı bırakıldı. Preoperatif değerlendirme vizitinde hastalara yapılacak işlem ve Vizuel Analog Skala (VAS, $0=a$ ğrı yok, 10=şiddetli ağrı) hakkında bilgi verildi. Postoperatif bulantı-kusma (PONV) 3 puanlı bir sistem (0:bulantı ve kusma yok, 1:bulantı mevcut, ancak kusma yok, 2:bulantı olan veya olmayan kusma) ile değerlendirildi.

Hastaların yaş, cinsiyet, boy, kilo gibi demografik özellikleri ile ameliyat süresi, taburculuk süresi ve hastalara uygulanan postoperatif analjezi yöntemi kaydedildi. Hastalar USG eşliğinde TAP blok (Grup 1), USG eşliğinde cerrahi kesi hattına LAİ infiltrasyonu (Grup 2) ve IVD (Grup 3) uygulananlar olarak 3 gruba ayrildı.

Bütün hastalara standart anestezi rejimi uygulandı. Preoperatif 6-8 saatlik açlık döneminden sonra hastalar işlem odasına alınd. Hastalara standart olarak kalp hızı (HR), non-invaziv arteryel basınç (NİAB), elektrokardiyogram (EKG) ve periferik oksijen saturasyon (Sp02) monitörizasyonu uygulandı. Periferik damar yolundan $0.02 \mathrm{mg} / \mathrm{kg}$ midazolam (Zolamid $5 \mathrm{mg} / 5 \mathrm{ml}$ amp, Vem, Turkey) ile premedikasyon yapıldı. 10-15 $\mathrm{ml} / \mathrm{kg}^{\prime}$ dan iv serum fizyolojik başlandı ve hasta oturur pozisyona alındı. Sterilizasyon sağlandıktan sonra deneyimli bir anesteziyolog tarafından 26 G quincke iğne (Egemen, İzmir, Turkey) ile L3-4 veya L4-5 intervertebral 
aralıktan subaraknoid ponksiyon yapıldı. Beyin omurilik sıvı akışı görüldükten sonra $12-15 \mathrm{mg}$ heavy bupivakain (Bupivon, Spinal heavy \%0,5, Onfarma, Turkey) ile spinal anestezi uyguland. Daha sonra hastalar supin pozisyona alındı. Cerrahi işlem başlamadan önce preemptif olarak Grup 1' deki hastalara USG eşliğinde TAP blok, Grup 2' deki hastalara cerrahi kesi hattına USG eşliğinde LAİ infiltrasyonu ve Grup 3' teki hastalara $50 \mathrm{mg}$ IVD uyguland. Motor blok, Bromage Skalası'nda 3'e (0: hiç paralizi yok, hasta ayağını ve dizini tam fleksiyona getirebilir; 1 : sadece dizini ve ayaklarını hareket ettirebilir, bacağını düz olarak kaldıramaz, kalça fleksiyonu mevcuttur; 2: diz fleksiyonu olmaz, sadece ayağını oynatabilir; 3: komple motor blok) ve sensoryal blok torakal 6-8 seviyesine ulaşınca cerrahi işleme izin verildi. Başarısız spinal anestezi durumunda genel anesteziye geçilerek bu hastalar çalışma dışı bırakıldı. Ameliyat süresince her $5 \mathrm{dk}$.'da bir kalp tepe atımı ve NİAB değerleri kaydedildi. Bradikardi ve/veya hipotansiyon gelișen hastalara atropin ve/veya efedrin ile müdahale edildi. Başarısız spinal anestezi uygulaması olanlar ile takip aşamasında kendi isteğiyle hastanemizden erken taburcu olan hastalar çıkarıldıktan sonra çalışmamız 120 hasta ile tamamlandı (Șekil 1).

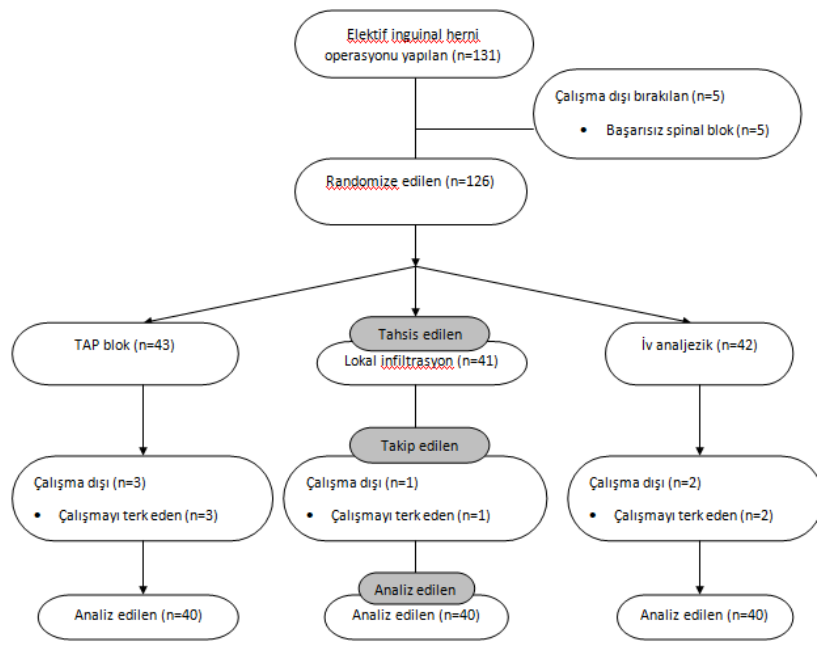

Figür 1: Çalışma Şeması
Transversus Abdominis Plan Bloğu Uygulaması

TAP blok, cerrahi işlem başlamadan önce USG eşliğinde (Esaote, MyLab Six, Netherlands) uygulandı. Sterilizasyon sağlandıktan sonra, lineer USG probu (5-10 MHz) iliak krest ve subkostal düzlemleri arasına orta aksiler hat üzerinde transvers olarak yerleştirildi (Şekil 2). USG ile cilt-cilt altı dokusu, eksternal oblik, internal oblik ve transversus abdominis kasları ve peritoneal kavite görüntülendi (Şekil 3). 20 G sinir bloğu iğnesi (Stimuplex Ultra 360, B.Braun, Melsungen, Germany), in-plane teknik ile görüntülenerek internal oblik ve transversus abdominis kasları arasındaki fasyal düzleme ilerletildi. 0,2 ile 0,4 mL normal salin verilerek hipoekoik görüntü ile enjeksiyon noktası doğrulandı. Daha sonra $20 \mathrm{~mL} \quad \% 0,25$ bupivakain (Buvasin \%0,5, İstanbul, Turkey) solüsyonu fasyal düzleme hidrodiseksiyon tekniğiyle aralıklı aspirasyon yapılarak enjekte edildi (Şekil 4). Bilateral olgularda işlem her iki tarafa da aynı şekilde uygulandı. Tüm bloklar deneyimli tek bir anesteziyolog tarafindan uygulandi.

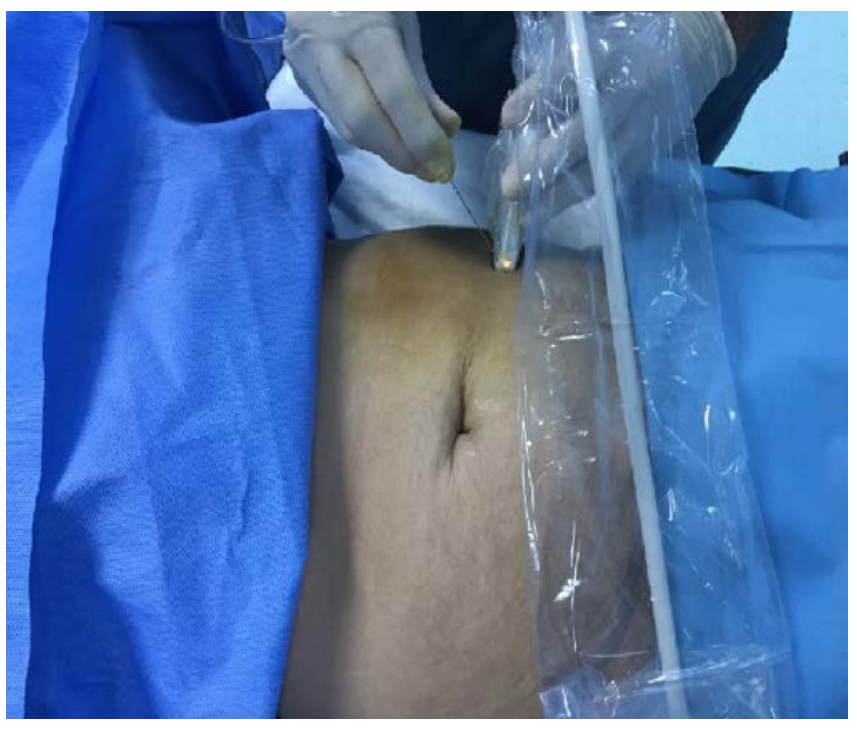

Figür 2: Transversus Abdominis Plan bloğu öncesi prob pozisyonu 


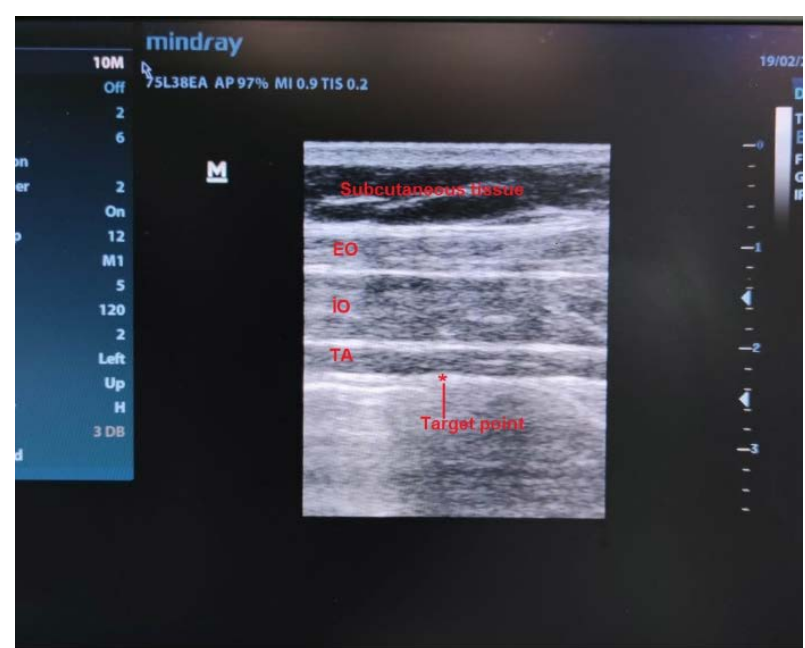

Figür 3: Transversus Abdominis Plan bloğu öncesi

EO: Eksternal Oblik. IO: Internal Oblik. TA: Transversus Abdominis.

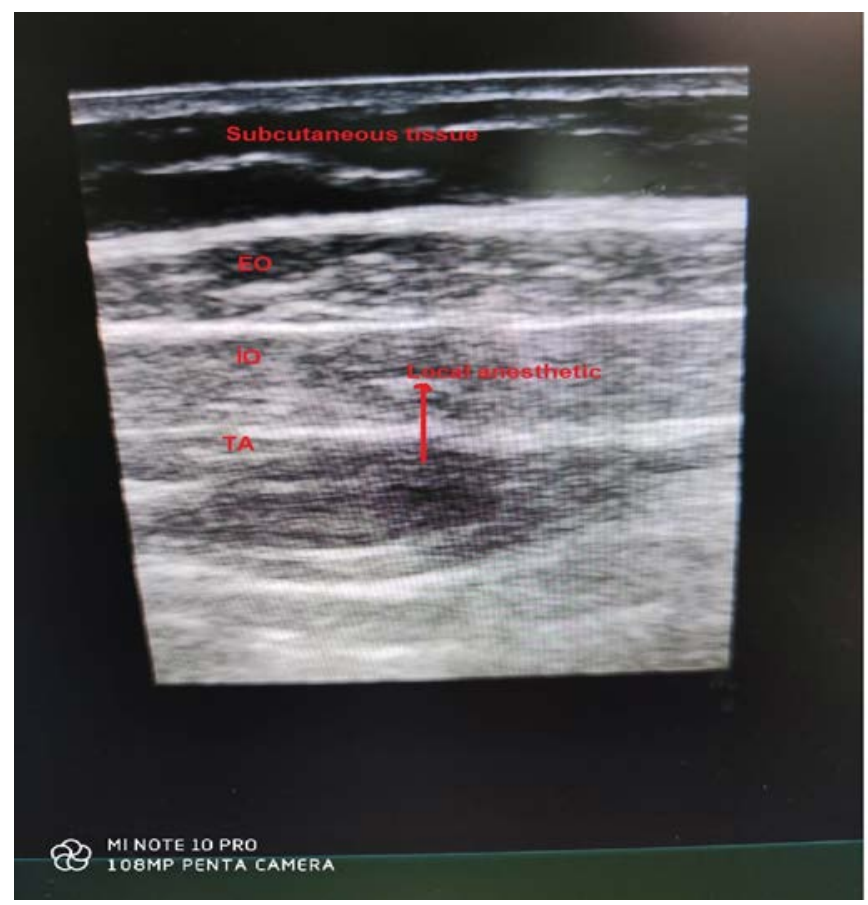

Figür 4: Transversus Abdominis Plan bloğu sonrası

EO: Eksternal Oblik. IO: Internal Oblik. TA: Transversus Abdominis.

Cerrahi Hat Lokal Anestezik İnfiltrasyonu Uygulaması

LAİ infiltrasyonu, cerrahi işlem başlamadan önce USG eşliğinde yapıldı. Lokal infiltrasyon kör teknikle uygulandığında yanlışlıkla cilt altı veya kas içine uygulanma nedeniyle yetersiz analjeziye yol açabilir. Hatta kas içi enjeksiyon şiddetli ağrı ile sonuçlanabilir. Bu açıdan lokal infiltrasyonun faysa altına yapılması analjezi sağlanması açısından önem arzetmektedir. $\mathrm{Bu}$ yüzden lokal infiltrasyon, kolay görüntülenebilinen faysal düzleme USG eşliğinde uygulanarak lokal anesteziğin dağılımı gözlemlendi. $\quad 10 \mathrm{~mL} \quad \% 0,25$ bupivakain solüsyonu, cerrah tarafından önceden işaretlenmiş insizyon yaplacak hattın çevresine, içine ve insizyon hattı ile fasya arasına $22 \mathrm{G}$ iğne ile negatif aspirasyondan sonra enjekte edildi (Şekil 5). Tüm LAİ infiltrasyonları deneyimli tek bir anesteziyolog tarafından yapıldı.

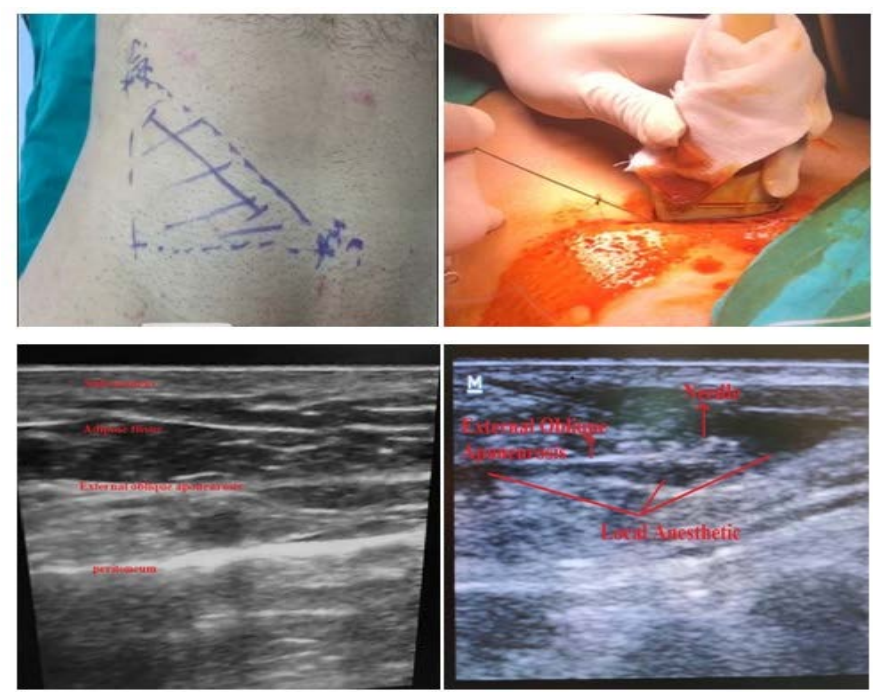

Figür 5: Ultrason eşliğinde lokal anestezik infiltrasyon

A: Lokal anestezik infiltrasyon öncesi işaretleme. B: Prob pozisyon. C: Inguinal bölgenin enjeksiyon öncesi USG ile görüntülenmesi. D: Blok sonrası ve lokal anestezik dağılımı.

\section{İntravenöz Deksketoprofen Uygulaması}

IVD grubundaki hastalara cerrahi başlamadan önce $50 \mathrm{mg}$ deksketoprofen trometamol (Metadem, 5mg/2ml amp, Vem, Turkey) iv yoldan uyguland. Hastalar taburcu olana kadar her 8 saatte bir 50mg deksketopropofen tekrarlanan dozlarda postoperatif dönemde de iv olarak verildi.

Hastalar, operasyon sonrası postanestezik bakım ünitesine alındı. Tüm hastalara postoperatif dönemde her 6 saatte bir $10 \mathrm{mg} / \mathrm{kg}$ parasetamol iv infüzyon uygulandı. Postoperatif ağrı şiddeti VAS skoru ile değerlendirildi. Postoperatif dönemde 30.dk, 1., 2., 4., 8., 12., 16. 
ve 24. saatlerde VAS skoru, bulantı-kusma skoru ve sedasyon skoru kaydedildi. VAS skoru 0 olanlar ağrı yok(mükemmel analjezi), $\leq 3$ olanlar kurtarıcı analjezik gerektirmeyen hafif ağrı olarak değerlendirildi. VAS skoru 4-6 olanlar orta şiddette ağrı ve 7-10 olanlar şiddetli ağrı olarak değerlendirilip, bu hastalara kurtarıcı analjezi amaciyla $100 \mathrm{mg}$ tramadol (Tramosel, 100mg/2ml amp, Haver, Turkey) iv yoldan verildi. VAS skoruna göre gereğinde 8 saatte bir iv tramadol maksimum $400 \mathrm{mg} /$ gün olarak verildi. 24 saatlik ortalama VAS skorları hesaplandı.

Postoperatif dönemde kurtarıcı analjezik ihtiyacı olan hasta sayısı, ilk analjezik gereksinim zamanı, analjezi süresi, tramadol tüketim miktarı, yan etki ve komplikasyonlar kaydedildi. Bulantı-kusma şikâyeti olan hastalara $4 \mathrm{mg}$ ondansetron (Kemoset, $8 \mathrm{mg} / 4 \mathrm{ml}$, Deva, Turkey) iv yoldan verildi. Postoperatif servis takibinin ardından herhangi bir problemi olmayan hastalar taburcu edildi.

Örneklem büyüklüğünün hesaplanmasında, GPower version 3.1.9.4 (Universität Kiel, Germany) programı kullanıldı. An alpha error of 0.05 , Power (1- $\beta$ err prob) 0.95, Numerator df 3 , Number of groups 3 ve effect size 0.4 kabul edilerek çalışmaya dâhil edilecek minimum hasta sayısı 112 olarak hesaplandı.

İstatistiksel analizler için SPSS 16.0 for Windows programı (SPSS Inc., Chicago, IL, USA) kullanıldı. İstatistiksel olarak sayısal veriler ortalama ve standart sapma; kategorik veriler ise frekans ve yüzde olarak ifade edildi. Gruplardaki kategorik verilerin karşılaştırılması kikare testi ile yapıldı, sonuçlar \% olarak verildi. Numerik verilerin normallik dağılımına uyup uymadığı KolmogorovSmirnov testi ile değerlendirildi. Normallik dağılımına uyan veriler One-way ANOVA testi ile değerlendirilirken, normallik dağılımına uymayan verilerin karşılaştırılmasında Kruskal-Wallis testi kullanıldı. Anlamlı çıkan değerler sonrası hangi gruplar arasında fark olduğu Post Hoc analizi ile değerlendirildi. Tüm karşılaştırmalarda $\mathrm{p}<0.05$ anlamlı kabul edildi.

\section{BULGULAR}

Çalışma boyunca 131 hasta takip edildi. 5 hasta başarısız spinal anestezi nedeniyle ve 6 hasta çalışmaya uyum sağlayamadığından çalışma dışı bırakıldı (Şekil 1). Gruplar arasında demografik veriler, ameliyat bölgesi ve cerrahi süre açısından istatistiksel olarak anlamlı bir fark saptanmadı (Tablo 1).

Tablo I: Demografik veriler ve klinik özellikler

\begin{tabular}{|c|c|c|c|c|}
\hline & $\begin{array}{c}\text { Grup1(n=40 } \\
) \\
\text { Mean } \pm S^{*}\end{array}$ & $\begin{array}{c}\text { Grup2 }(n=40 \\
) \\
\text { Mean } \pm \text { SD }\end{array}$ & $\begin{array}{c}\text { Grup3(n=40 } \\
\text { ) } \\
\text { Mean } \pm \text { SD }\end{array}$ & $\underset{\substack{p \\
\text { deger }}}{\stackrel{p}{a}}$ \\
\hline Yaş (yıl) & $46.73 \pm 15.05$ & $48.68 \pm 15.10$ & $51.48 \pm 16.23$ & 0.389 \\
\hline Boy $(\mathrm{cm})$ & $173.05 \pm 6.11$ & $173.30 \pm 6.32$ & $173.83 \pm 4.16$ & 0.821 \\
\hline Kilo (kg) & $73.35 \pm 8.67$ & $72.13 \pm 10.79$ & $74.50 \pm 7.50$ & 0.507 \\
\hline $\mathbf{V K} \dot{I}^{* *}$ & $24.45 \pm 2.30$ & $23.89 \pm 2.25$ & $24.65 \pm 2.38$ & 0.308 \\
\hline $\begin{array}{l}\text { Cinsiyet } \\
\text { (Erkek / } \\
\text { Kadın) }\end{array}$ & $38 / 2$ & $39 / 1$ & $36 / 4$ & 0.346 \\
\hline $\begin{array}{l}\text { Cerrahi süre } \\
\text { (dakika) }\end{array}$ & $58.88 \pm 18.75$ & $56.38 \pm 14.89$ & $53.25 \pm 17.30$ & 0.339 \\
\hline Cerrahi Bölge & & & & 0.058 \\
\hline Sağ & 24 & 23 & 20 & \\
\hline Sol & 16 & 17 & 20 & \\
\hline
\end{tabular}

*Standart Deviation: **Vücut Kitle İndeksi

Postoperatif ilk 24 saatlik dönemde hasta başına ortalama tramadol tüketim miktarları

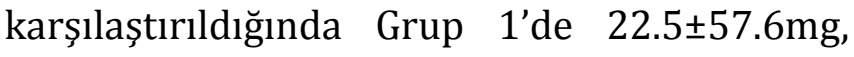

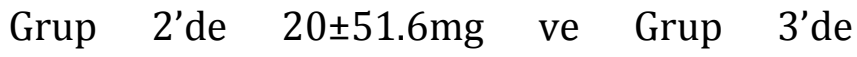
$27.5 \pm 59.8 \mathrm{mg}$ olarak tespit edildi. Gruplar arasında istatistiksel olarak anlamlı bir fark saptanmadı (Tablo 2).

Postoperatif takip saatlerinin herhangi birinde VAS skoru $\leq 3$ (hafif ağrı) olup tramadol ihtiyacı olmayanlar Grup 1'de \%85(n=34), Grup 2'de $\% 85(n=34)$ ve Grup 3'de \%80(n=32) olarak tespit edildi. VAS skoru 4-6(orta derecede ağrı) olan hasta oranı Grup 1'de \%15(n=6), Grup 2'de $\% 15(n=6)$ ve Grup 3'te $\% 20(n=8)$ olarak tespit edildi. Tüm gruplarda VAS skoru 7-10(şiddetli 
ağrı) olan hiçbir hastaya rastlanmadı. Gruplar arasında istatistiksel olarak anlamlı bir fark saptanmadı (Tablo 2,3).

Tablo II: Kurtarıcı analjezik ihtiyacı, opioid tüketimi ve komplikasyon

\begin{tabular}{|c|c|c|c|c|}
\hline & $\begin{array}{c}\text { Grup1 } \\
(n=40 \\
)\end{array}$ & $\begin{array}{c}\text { Grup2 } \\
\text { (n=40 } \\
\text { ) }\end{array}$ & $\begin{array}{c}\text { Grup3 } \\
\text { (n=40 } \\
\text { ) }\end{array}$ & $\begin{array}{c}\text { p } \\
\text { değ } \\
\text { eri }\end{array}$ \\
\hline $\begin{array}{l}\text { Kurtarıcı analjezik ihtiyacı olan } \\
\text { hasta sayısı (\%) }\end{array}$ & $6(15)$ & $6(15)$ & $8(20)$ & 0.787 \\
\hline Opioid tüketimi (ortalama mg / kg) & $\begin{array}{c}22.5 \pm 57 \\
.6\end{array}$ & $20 \pm 51.6$ & $\begin{array}{c}27.5 \pm 59 \\
.8\end{array}$ & 0.833 \\
\hline Postoperatif analjezi süresi (saat) & $\begin{array}{c}21.0 \pm 7 \\
3\end{array}$ & $\begin{array}{c}21.2 \pm 6 . \\
7\end{array}$ & $\begin{array}{c}21.4 \pm 5 \\
7\end{array}$ & 0.960 \\
\hline $\begin{array}{l}\text { Komplikasyon } \\
\text { vezikale) }\end{array}$ & $6(\% 15)$ & $0(\% 0)$ & $2(\% 5)$ & $\begin{array}{r}0.024 \\
* *\end{array}$ \\
\hline
\end{tabular}

* Postoperatif bulantı-kusma; ${ }^{* *}$ statistically significant

Tablo III: Vizüel analog skala değerleri ve kurtarıcı opioid dozu

\begin{tabular}{|c|c|c|c|c|c|c|}
\hline \multirow{2}{*}{ Grup } & \multirow{2}{*}{$\mathbf{V A S}^{*}$} & \multicolumn{3}{|c|}{$\begin{array}{c}\text { Ortalama tramadol } \\
\text { tüketimi }\end{array}$} & \multirow{2}{*}{\multicolumn{2}{|c|}{ Toplam }} \\
\hline & & $\mathbf{0}$ & $\begin{array}{l}0-100 \\
\mathrm{mg}\end{array}$ & $\begin{array}{l}100-300 \\
\mathrm{mg}\end{array}$ & & \\
\hline \multirow{4}{*}{ Grup 1} & $\leq 3$ (hafif) & 34 & 0 & 0 & \multicolumn{2}{|c|}{$34(\% 85)$} \\
\hline & 4-6(orta) & 0 & 3 & 3 & \multicolumn{2}{|c|}{$6(\% 15)$} \\
\hline & $\begin{array}{c}7- \\
10 \text { (şiddetli) }\end{array}$ & 0 & 0 & 0 & \multicolumn{2}{|c|}{0} \\
\hline & Toplam & \multicolumn{3}{|c|}{40} & \multicolumn{2}{|c|}{$40(\% 100)$} \\
\hline \multirow{4}{*}{ Grup 2} & $\leq 3$ (hafif) & 34 & \multicolumn{2}{|r|}{0} & 0 & $\begin{array}{c}34(\% 8 \\
5)\end{array}$ \\
\hline & $4-6$ (orta) & 0 & \multicolumn{2}{|r|}{4} & 2 & $\begin{array}{c}6(\% 15 \\
)\end{array}$ \\
\hline & $\begin{array}{c}7- \\
10(\text { şiddetli) }\end{array}$ & 0 & \multicolumn{2}{|r|}{0} & 0 & 0 \\
\hline & Toplam & \multicolumn{3}{|c|}{40} & \multicolumn{2}{|c|}{$40(\% 100)$} \\
\hline \multirow{4}{*}{ Grup 3} & $\leq 3$ (hafif) & 32 & \multicolumn{2}{|r|}{0} & 0 & $\begin{array}{c}32(\% 8 \\
0)\end{array}$ \\
\hline & 4-6(orta) & 0 & \multicolumn{2}{|r|}{5} & 3 & $\begin{array}{c}8(\% 20 \\
)\end{array}$ \\
\hline & $\begin{array}{c}7- \\
10 \text { (şiddetli) }\end{array}$ & 0 & \multicolumn{2}{|r|}{0} & 0 & 0 \\
\hline & Toplam & \multicolumn{3}{|c|}{40} & \multicolumn{2}{|c|}{$40(\% 100)$} \\
\hline
\end{tabular}

Postoperatif analjezi süresi Grup 1'de

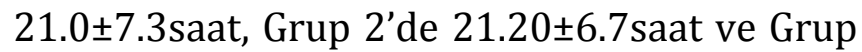

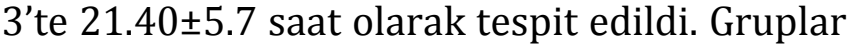
arasında istatistiksel olarak anlamlı bir fark saptanmadı (Tablo 2).

30.dk, 1., 2., 4., 8. ve 12. saatlerdeki VAS skorları Grup 1'de diğer gruplara göre istatistiksel olarak daha düşük saptandı (p değerleri sirasiyla 0.003, 007, 0013, 0049, 0015, 0021). 16. ve 24.saatlerde ise tüm gruplarda benzer sonuçlar tespit edildi. 24 saatlik ortalama VAS değerleri Grup 1'de 0.95, Grup 2'de 1.32 ve Grup 3'te 1.57 olarak tespit edildi. Grupları kendi aralarında karşılaștırmak için ek bir analiz yapıldı. Grup 1'de 30.dk ve 2. saatteki VAS skorları Grup 2'ye göre daha düşük saptandı (p değerleri sirasıyla 0.049, 0.037). Diğer takiplerde ise 2 grup arasında istatistiksel olarak anlamlı fark yoktu. Aynı zamanda 30.dk, 1., 2., 8. ve 12. saatlerdeki VAS skorları Grup 1'de Grup 3'e göre daha düşük iken ( $\mathrm{p}$ değerleri sirasıyla 0.003, 0.006, 0.021, 0.017, 0.016) diğer takiplerde benzerdi. Grup 2 ile Grup 3 tüm saatlerdeki VAS skorları açısından karşılaştırıldığında ise istatistiksel olarak anlamlı bir fark yoktu (Tablo 4, Şekil 6).

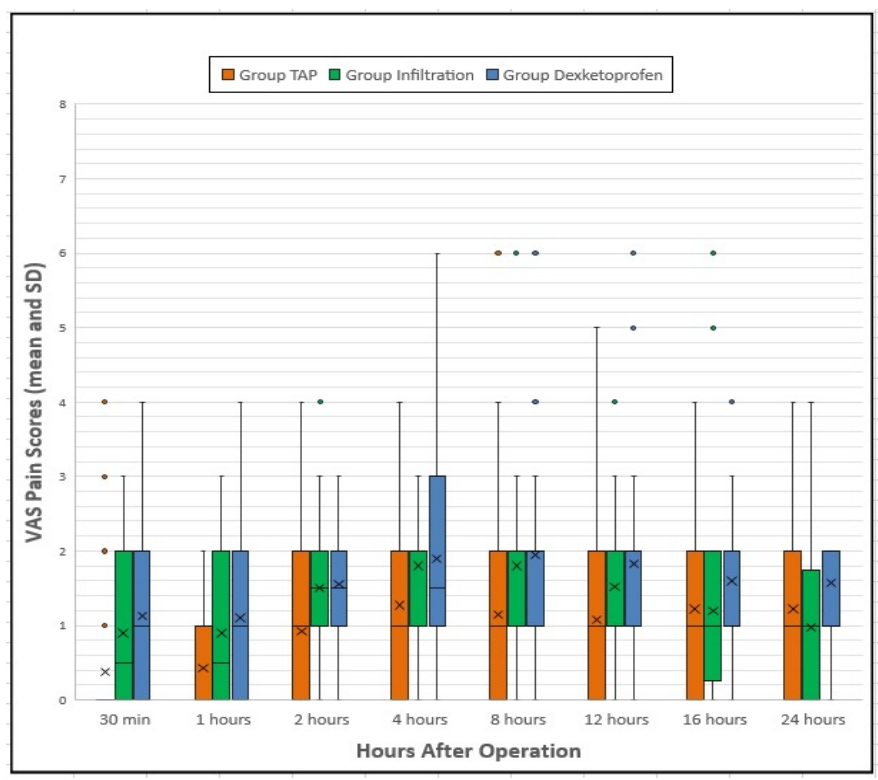

Figür 6: Tüm gruplarda postoperatif vizüel analog skala skoru.

TAP: Transversus abdominis plane; VAS: Vizüel analog skala 
Tablo IV: Ortalama Vizüel Analog Skala değeri [Mean (min - max)]

\begin{tabular}{|c|c|c|c|c|c|c|c|}
\hline & $\begin{array}{l}\text { Grup } 1 \\
(n=40)\end{array}$ & $\begin{array}{c}\text { Grup2 } \\
(n=40 \\
\text { ) }\end{array}$ & $\begin{array}{c}\text { Grup3 } \\
(n=40 \\
)\end{array}$ & $\begin{array}{c}\text { p } \\
\text { değe } \\
\text { ri }\end{array}$ & $\begin{array}{c}\text { Post- } \\
\text { hoc } \\
\text { p } \\
\text { (Grup } \\
1 \text { ve } \\
\text { 2) }\end{array}$ & $\begin{array}{l}\text { Post- } \\
\text { hoc p } \\
\text { (Grup } \\
1 \text { ve } \\
\text { 3) }\end{array}$ & $\begin{array}{c}\text { Post- } \\
\text { hoc p } \\
\text { (Grup } \\
2 \text { ve } \\
\text { 3) }\end{array}$ \\
\hline 30.dk & $0.38(0-4)$ & $\begin{array}{r}0.90(0- \\
3)\end{array}$ & $\begin{array}{r}1.13(0- \\
4)\end{array}$ & $0.003^{*}$ & $0.049 *$ & $0.003 *$ & 0.564 \\
\hline 1.saat & $0.43(0-4)$ & $\begin{array}{r}0.90(0- \\
3)\end{array}$ & $\begin{array}{r}1.10(0- \\
4)\end{array}$ & $0.007^{*}$ & 0.072 & $0.006^{*}$ & 0.619 \\
\hline 2. saat & $0.93(0-4)$ & $\begin{array}{r}1.50(0- \\
4)\end{array}$ & $\begin{array}{r}1.55(0- \\
3)\end{array}$ & $0.013^{*}$ & $0.037^{*}$ & $0.021 *$ & 0.974 \\
\hline 4. saat & $1.28(0-4)$ & $\begin{array}{r}1.80(0- \\
4)\end{array}$ & $\begin{array}{c}1.90(0- \\
6)\end{array}$ & $0.049^{*}$ & 0.130 & 0.057 & 0.927 \\
\hline 8. saat & $1.15(0-6)$ & $\begin{array}{r}1.80(0- \\
6)\end{array}$ & $\begin{array}{c}1.95(0- \\
6)\end{array}$ & $0.015^{*}$ & 0.065 & $0.017 *$ & 0.861 \\
\hline 12. saat & $1.08(0-5)$ & $\begin{array}{r}1.53(0- \\
4)\end{array}$ & $\begin{array}{c}1.83(0- \\
6)\end{array}$ & $0.021 *$ & 0.215 & $0.016^{*}$ & 0.501 \\
\hline 16. saat & $1.23(0-6)$ & $\begin{array}{r}1.20(0- \\
6)\end{array}$ & $\begin{array}{r}1.60(0- \\
4)\end{array}$ & 0.285 & 0.996 & 0.379 & 0.333 \\
\hline 24. saat & $1.23(0-6)$ & $\begin{array}{r}0.98(0- \\
4)\end{array}$ & $\begin{array}{r}1.58(0- \\
4)\end{array}$ & 0.069 & 0.598 & 0.367 & 0.056 \\
\hline $\begin{array}{l}\text { Ortala } \\
\text { ma }\end{array}$ & 0.95 & 1.32 & 1.57 & & & & \\
\hline
\end{tabular}

* statistically significant

Grup 1'de \%15 (n=6), Grup 3'de \%5 (n=2) hastada komplikasyon görülmesine karşın Grup 2'de hiçbir hastada komplikasyon görülmedi (Tablo 2). Diğer gruplarla karşılaştırıldığında Grup 1' deki komplikasyon oranı istatistiksel olarak daha yüksek saptandı $(\mathrm{p}=0.024)$. Grup 1'deki 1 hastada glob vezikale gelişti. Mesane sonda uygulaması ile tedavi edildi. Diğer komplikasyonların tamamı bulantı olup $8 \mathrm{mg}$ iv ondansetron ile tedavi edildi.

Sedasyon skorları açısından gruplar arasında istatistiksel olarak anlamlı bir fark saptanmadı.

\section{TARTIŞMA}

İngunal herni operasyonlarında preemptif olarak uygulanan TAP bloğu, LAİ infiltrasyonu ve IVD yöntemlerini karşılaştırdığımız prospektif gözlemsel çalışmamızda, postoperatif opioid tüketim miktarı ve kurtarıcı analjezik ilaç ihtiyacı olan hasta sayılarını istatistilsel olarak benzer bulduk. Bunun yanında, hasta konforunun bir belirteci olan VAS skorlarını LAİ infiltrasyonu ve İV uygulamalarında benzer, TAP blok uygulamasında ise diğer iki yönteme göre daha düşük olarak saptadık.

TAP bloğunun postoperatif opioid tüketimini azalttığı, erken mobilizasyon sağladığı ve yaşam kalitesini arttırdığ bilinmektedir ${ }^{15}$. Salman ve ark. spinal anestezi eşliğinde landmark tekniğiyle TAP blok uygulananlarda plasebo grubuna oranla daha düşük opioid tüketimi olduğunu bildirmişlerdir ${ }^{16}$. Yine bununla birlikte USG eşliğinde TAP blok uygulananlarda, LAI infiltrasyonu uygulananlara göre postoperatif dönemde daha düşük miktarda opioid tüketimi olduğu araştırmacılar tarafından rapor edilmiştir ${ }^{17,18}$. Petersen ve ark. ise diğer çalışmalardan farklı olarak preemptif LAİ infiltrasyonu ve TAP blok uygulamışlar ve postoperatif ilk 2 saatte LAI infiltrasyonu grubunda USG eşliğinde TAP blok ve plasebo gruplarına göre daha düşük miktarda opioid tüketiminin olduğunu ancak 2-24 saatlik dönemde gruplar arasında anlamlı bir fark olmadığını belirtmişlerdir ${ }^{2}$. Preemptif olarak uyguladığımız TAP blok ile LAİ infiltrasyonunu postoperatif opioid tüketim miktarları açısından karşılaştırdığımızda, literatürdeki yayınların aksine her iki yöntemin de benzer sonuçlara yol açtığını saptadık. Ayrıca bulgularımız, Petersen ve ark.'nın postoperatif ilk 2 saatlik dönemdeki sonuçlarıyla çelişmesine rağmen 2-24 saatlik sonuçlarıyla benzerlik göstermektedir. $\mathrm{Bu}$ sonuca ulaşmamızda, kör teknikle yapılan LAİ infiltrasyonunun cilt altı veya kas içi gibi yanlış lokalizasyonların aksine USG kullanılarak doğru lokalizasyona uygulanmasının etkili olduğunu düşünmekteyiz. 
Plasebo kontrollü çalışmalarda IVAİ uygulamasının tek başına kurtarıcı analjezik kullanımını azalttığı bildirilmiştir ${ }^{1,19}$. LAİ infiltrasyonu ile nsaii uygulamasinı karşılaştıran çalışmalarda ise gruplar arasında benzer sonuçlar olduğu belirtilmiştir1. Sadece IVAİ uygulanan hastalar ile USG eşliğinde TAP blok+ IVAİ uygulanan hastaların karşılaştırıldığı çalışmalarda, TAP blok uygulanan grupta postoperatif dönemde daha düşük miktarda kurtarıcı opiod tüketimi olduğu saptanmıştır5,15. $\mathrm{Bu}$ konudaki literatür değerlendirmemizde, farklı ilaçlarla uygulanan preemptif IVAİ ile TAP blok veya LAI infiltrasyonu karşılaştırmaları olmasına rağmen, bu uygulamaların preemptif deksketoprofen ile karşılaştırıldığı herhangi bir çalışmaya rastlayamadık. Çalışmamızda, preemptif iv deksketoprofen uygulaması ile TAP blok ve LAİ infiltrasyonu arasında postoperatif opioid tüketim miktarları açısından herhangi bir fark olmadığını saptadık. Bu sonucun, Long ve ark.'nın da belirttiği gibi cerrahi travmaya bağlı afferent ağrı sinyallerinin santral sinir sistemine ulaşmasını engellemede preemptif IVAİ uygulamasının da diğer yöntemler kadar yeterli etkisinden kaynaklandığını düşünmekteyiz ${ }^{20}$.

Bıçak ve ark. laparoskopik kolesistektomi operasyonu geçiren hastalarda preemptif analjezik yöntemleri karşılaştırmışlar ve iv deksketoprofen uygulananlarda $\% 36,9$, lokal infiltrasyon uygulananlarda $\% 46,9$ ve TAP blok uygulananlarda $\% 3$ oranında hastada postoperatif dönemde ek analjezik ihtiyacı olduğunu rapor etmişlerdir ${ }^{21}$. Kendigelen ve ark. 80 hastayı kapsayan çalışmalarında, TAP blok grubunda \%32,5 hastada, LAİ infiltrasyonu grubunda ise $\% 100$ hastada postoperatif ilk 24 saatlik dilimde analjezik ihtiyacı olduğunu bildirmişlerdir ${ }^{17}$. Talip ve ark. 100 hastayı inceledikleri çalışmalarında, ek opioid ihtiyacı olan hasta sayısını USG eşliğinde TAP blok grubunda \%8, LAİ infiltrasyonu grubunda ise
\%84 olarak tespit etmisslerdir ${ }^{18}$. Beyoğlu ve ark. ise IVAI ile USG eşliğinde TAP blok+ IVAİ uygulamalarını karşılaştırmışlar ve TAP blok grubunda postoperatif dönemde daha az sayıda hastada kurtarıcı analjezik ihtiyacı olduğunu saptamışlardır ${ }^{5}$. Çalışmamızda, preemptif olarak uygulanan IVD, TAP blok ve LAI infiltrasyonu arasında postoperatif kurtarıcı analjezik ilaç ihtiyacı olan hasta sayıları açısından herhangi bir fark olmadığını saptadık. TAP blok ile LAİ infiltrasyonu gruplarını birbirleriyle karşılaștırdığımızda ise önceki çalışmaların aksine her iki grupta da benzer sonuçlar bulduk. Bu sonuca ulaşmamızda, ilk olarak LAİ infiltrasyonunun USG eşliğinde doğru lokalizasyona uygulanmasının etkili olduğunu düşünmekteyiz. Çünkü kör teknik ile yapılan LAİ işleminin cilt altı veya kas içi gibi yanlış lokalizasyonlara uygulanma ihtimali vardır. Yine önceki çalışmaların çoğunda genel anestezi ile operasyon gerçekleştirildi. Çalışmamızda ise spinal anestezi ile operasyon gerçekleştirildi. Spinal anestezinin genel anesteziden daha fazla postoperatif analjeziye katkı sunması çalışmamızda daha az hasta da kurtarıcı analjezik ihtiyacı olmasında bir diğer faktör olabilir. Ancak bunun daha ileri klinik çalışmalarla değerlendirilmesi gerektiğini düşünmekteyiz.

İnguinal herni ameliyatlarında, postoperatif analjezi amaciyla uygulanan TAP blok veya LAI infiltrasyonunda postoperatif 24-48 saatlik dönemdeki ağrı skorlarının plaseboya göre daha düşük olduğu saptanmıştır9,22,23. TAP blok ile LAİ infiltrasyonu veya TAP blok ile konvansiyonel sistemik analjeziyi karşılaştıran çalışmalarda, TAP blok uygulananlarda daha düșük ortalama VAS skorlarının olduğu bildirilmiştir ${ }^{15,18}$. Joshi ve ark. LAİ infiltrasyonu ile alan bloklarında benzer ağrı skorları olduğunu, LAİ infiltrasyonu ile İVAİ uygulaması karşılaştırıldığında ise LAİ infiltrasyonu uygulananlarda daha düşük ağrı skorları olduğunu sistematik derlemelerinde 
belirtmișlerdir ${ }^{1}$. Petersen ve ark. USG eșliğinde TAP blok, USG kullanılmaksızın uygulanan LAI infiltrasyonu ve plaseboyu değerlendirdikleri çalışmalarında önceki çalışmaların aksine LAİ infiltrasyonu grubunda postoperatif ilk 6 saatte daha düşük VAS skorları tespit etmişlerdir². Yücel ve ark. preemptif ilioinguinaliliohipogastrik sinir bloğu ve blok+iv deksketoprofen gruplarını kontrol grubuyla değerlendirmişler ve postoperatif ilk 12 saatlik dönemde deksketoprofen kullanılan grupta diğer 2 gruba göre daha düşük VAS skorları saptamışlardır ${ }^{24}$. Bizim çalışmamızda postoperatif ilk 12 saatlik dönem VAS skorlarını TAP blok grubunda diğer iki gruba göre daha düşük, 12-24 saatlik dönem VAS skorlarını ise tüm gruplarda benzer saptadık. Grupları kendi aralarında karşılaştırdığımızda, Petersen ve ark.'nın aksine 30.dk ve 2 . saatteki VAS skorlarını TAP blok grubunda LAİ infiltrasyonu grubuna göre daha düşük, diğer saatlerdeki VAS skorlarını ise her iki uygulamada da benzer olarak tespit ettik. Her iki grupta da $30 \mathrm{dk}$ ve 2 . saat haricindeki VAS skorlarını Joshi ve ark. gibi benzer olarak bulduk. Postoperatif VAS skorları açısından LAİ infiltrasyonu ile IVD'yi kendi aralarında karșılaștırdığımızda ise Joshi ve ark.'nın aksine her iki uygulamada da benzer olarak tespit ettik.

Theodoraki ve ark. inguinal herni operasyonu geçiren 60 hasta ile yaptıkları çalışmalarında TAP blok grubunda \%17,2 ve plasebo grubunda $\% 30$ hastada PONV geliștiğini bildirmișlerdir ${ }^{22}$. Talib ve ark. ise 100 hastayı kapsayan çalışmalarında PONV oranını TAP blok grubunda \%21,7, LAİ infiltrasyonu grubunda $\% 78,3$ olarak saptamışlardır ${ }^{18}$. Çalışmamızda TAP blok grubunda \%12,5, IVD grubunda $\% 5$ oranında bulantı tespit etmemize rağmen LAİ infiltrasyonu grubunda hiçbir hastada bulantıya rastlamadık. Önceki çalışmalarda her hastaya postoperatif dönemde düzenli periyotlarda NSAIİ kullanıldığı gözlendi. Biz ise parasetamol kullandık. NSAIII kullanımında gastrointestinal sistem irritasyonuna bağlı bulantı-kusma daha sık görülebilir. Önceki çalışmalara göre bulantıkusma açısından fark elde etmemiz, NSAï yerine parasetamol tercih etmemizden kaynaklanıyor olabilir. Yine hiçbir hastada TAP blok ve LAİ infiltrasyon işlemlerine bağlı herhangi bir yan etki veya komplikasyon ile karşılaşmadık.

Sonuç olarak; spinal anestezi eşliğinde inguinal herni onarımı yapılan hastalarda postoperatif analjezi amaciyla preemptif olarak TAP blok, LAI infiltrasyonu veya iv deksketoprofen kullanılabilir. $\mathrm{Bu}$ uygulamaların postoperatif opiod tüketim miktarı ve kurtarıcı analjezik ilaç ihtiyacı olan hasta sayısı üzerine olan etkileri benzerdir. Ancak TAP blok uygulamasının postoperatif ilk 24 saatte daha düşük VAS değerlerine sahip olması ve daha fazla sayıda hastada mükemmel analjezi sağlaması, TAP bloğun hasta konforu açısından diğer uygulamalara göre daha etkin olduğunu göstermektedir. LAİ infiltrasyonunun USG eşliğinde doğru lokalizasyona uygulanması da postoperatif analjezi kalitesini arttırabilir. Ancak bu işlemlerin preemptif uygulanmasiyla ilgili daha ayrıntılı ve kapsamlı çalışmalar yapılması gerektiğini düşünmekteyiz.

\section{Limitasyon}

Taburculuk süresi, hareket ile ağrı ve kronik ağrı değerlendirilmemesi çalışmamızın eksiklikleridir.

Etik Kurul Kararı: Çalışmamız için Etik Kurul onayı alındı ve çalışma Helsinki Bildirgesi'ne uygun olarak yürütüldü (Gazi Yaşargil Eğitim ve Araştırma Hastanesi. (Etik kurul tarihi ve no: 08.02.2019-225).

Çıkar Çatışması Beyanı: Yazarlar çıkar çatışması olmadığını bildirmişlerdir.

Finansal Destek: Bu çalışma her hangi bir fon tarafından desteklenmemiștir. 
Declaration of Conflicting Interests: The authors declare that they have no conflict of interest.

Financial Disclosure: No financial support was received.

\section{KAYNAKLAR}

1. Joshi GP, Rawal N, Kehlet H. Evidence-based management of postoperative pain in adults undergoing open inguinal hernia surgery. Br J Surg 2012; 99: 168-85.

2. Petersen PL, Mathiesen O, Stjernholm P, et al. The effect of transversus abdominis plane block or local anaesthetic infiltration in inguinal hernia repair: A randomised clinical trial. Eur J Anaesthesiol 2013; 30: 415-21.

3. Tsai H-C, Yoshida T, Chuang T-Y, et al. Transversus Abdominis Plane Block: An Updated Review of Anatomy and Techniques. Biomed Res Int 2017; 2017: 1-12.

4. Nir RR, Nahman-Averbuch H, Moont R, Sprecher E, Yarnitsky D. Preoperative preemptive drug administration for acute postoperative pain: A systematic review and meta-analysis. Eur J Pain 2016; 20: 1025-43.

5. Akyol Beyoğlu C, Ozdilek A, Erbabacan E, et al. Evaluation of the effects of subcostal transversus abdominis plane block on acute and subacute pain development following inguinal herniography: Randomized clinical study. Agri 2018; 30: 123-9.

6. Rafi AN. Abdominal field block via the lumbar triangle revisited. Anaesthesia 2012; 67: 1399-401.

7. Hebbard P, Fujiwara Y, Shibata Y, Royse C. Ultrasound-guided transversus abdominis plane (TAP) block. Anaesth Intensive Care 2007; 35: 6168.

8. Tuite D, Power C, Laffey JG, Sc B. Transversus Abdominis Plane Block: A Cadaveric and Radiological Evaluation. Reg Anesth Pain Med 2007; 32: 399-404.

9. Dierking GW, Østergaard E, Østergaard HT, Dahl JB. The effects of wound infiltration with bupivacaine versus saline on postoperative pain and opioid requirements after herniorrhaphy. Acta anaesthesiologica scandinavica 1994; 38: 289-92.
10. Kahramansoy N. Inguinal hernioraphy under local anesthesia in the elderly patients. Dicle Tip Derg 2012; 39: 5 13-7.

11. Englbrecht JS, Pogatzki-Zahn EM. Perioperative schmerztherapie bei abdominellen und thorakalen operationen. Schmerz 2014; 28: 265-81.

12. Helander EM, Eskander JP, Juneau CL, et al. Preemptive Analgesia, Regional Anesthesia, and Prevention of Chronic Postoperative Pain. Essentials Reg Anesth 2018; 445-62.

13. Hanna M, Moon JY. A review of dexketoprofen trometamol in acute pain. Curr Med Res Opin 2019; 35: 189-202.

14. Özyılmaz MA, Ölmez G, Deniz AA. Kaudal bupivakain, bupivakain-morfin ve bupivakainmidazolam karışımlarının çocuklarda preemtif analjezik etkinliğinin karşılaş̧ırılması. Dicle Tip Derg 2003; 1: 118-23.

15. Jain S, Kalra S, Sharma B, Sahai C, Sood J. Evaluation of Ultrasound - Guided Transversus Abdominis Plane Block for Postoperative Analgesia in Patients Undergoing Intraperitoneal Onlay Mesh Repair. Anesth Essays Res 2019; 13: 126-31.

16. Salman AE, Yetişir F, Yürekli et al. The efficacy of the semi-blind approach of transversus abdominis plane block on postoperative analgesia in patients undergoing inguinal hernia repair: a prospective randomized double-blind study. Local Reg Anesth 2013; 6: 1-7.

17. Kendigelen P, Tutuncu AC, Erbabacan E, et al. Ultrasound-assisted transversus abdominis plane block vs wound infiltration in pediatric patient with inguinal hernia: Randomized controlled trial. J Clin Anesth 2016; 30: 9-14.

18. Talib MT, Sikander RI, Ahsan MF. Ultrasound guided transversus abdominis plane (TAP) block is better than local wound infiltration for postoperative pain management in inguinal hernia repair. Anaesthesia, Pain \& Intensive Care 2015; 19: 457-62.

19. Ma N, Duncan JK, Scarfe AJ, Schuhmann S, Cameron AL. Clinical safety and effectiveness of transversus abdominis plane (TAP) block in postoperative analgesia: a systematic review and metaanalysis. J Anesth 2017; 31: 432-52. 
20. Long JB, Bevil K, Giles DL. Preemptive Analgesia in Minimally Invasive Gynecologic Surgery. J Minim Invasive Gynecol 2019; 26: 198-218.

21. Bıçak M, Salık F, Akelma H. Laparoskopik Safra Kesesi Ameliyatlarında Transversus Abdominis Plan Bloğu, İntravenöz Non-Steroid Anti İnflamatuar İlaç ve Lokal Anestezik İnfiltrasyonunun Karşılaştırılması. Harran Üniversitesi Tıp Fakültesi Derg 2020; 17: 74-81.

22. Theodoraki K, Papacharalampous $P$, Tsaroucha A, Vezakis A, Argyra E. The effect of transversus abdominis plane block on acute and chronic pain after inguinal hernia repair. A randomized controlled trial. Int J Surg 2019; 63: 63-70.

23. Venkatraman R, Abhinaya RJ, Sakthivel A, Sivarajan G. Efficacy of ultrasound-guided transversus abdominis plane block for postoperative analgesia in patients undergoing inguinal hernia repair. Local Reg Anesth 2016; 9: 712.

24. Yucel E, Kol IO, Duger C, et al. Ilioinguinaliliohypogastric nerve block within travenous dexketoprofen improves postoperative analgesia in abdominal hysterectomies. Rev Bras Anestesiol 2013; 63: 334-9. 